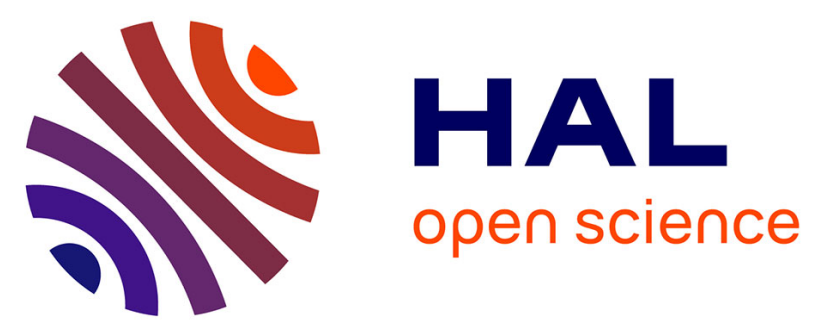

\title{
Synovitis and tenosynovitis of the hands and wrists in patients with SSc: The need for a consensus definition of sclerosing tenosynovitis
}

Leila Caillault, Catherine Droitcourt, François Robin, Marine Tas, Guillaume Coiffier, Alain Lescoat

\section{To cite this version:}

Leïla Caillault, Catherine Droitcourt, François Robin, Marine Tas, Guillaume Coiffier, et al.. Synovitis and tenosynovitis of the hands and wrists in patients with SSc: The need for a consensus definition of sclerosing tenosynovitis. Seminars in Arthritis and Rheumatism, 2022, 52, pp.151901. 10.1016/j.semarthrit.2021.08.009 . hal-03359429

\author{
HAL Id: hal-03359429 \\ https://hal.science/hal-03359429
}

Submitted on 15 Oct 2021

HAL is a multi-disciplinary open access archive for the deposit and dissemination of scientific research documents, whether they are published or not. The documents may come from teaching and research institutions in France or abroad, or from public or private research centers.
L'archive ouverte pluridisciplinaire $\mathbf{H A L}$, est destinée au dépôt et à la diffusion de documents scientifiques de niveau recherche, publiés ou non, émanant des établissements d'enseignement et de recherche français ou étrangers, des laboratoires publics ou privés. 
Synovitis and tenosynovitis of the hands and wrists in patients with SSc: the need for a consensus definition of sclerosing tenosynovitis.

\author{
Leila Caillault ${ }^{1}$, Catherine Droitcourt ${ }^{2}$, François Robin ${ }^{3}$, Marine Tas $^{4}$, \\ Guillaume Coiffier ${ }^{1,5}$, Alain Lescoat ${ }^{1,6^{*}}$
}

1 : Department of Internal Medicine and Clinical Immunology, CHU Rennes, University of Rennes 1, Rennes, France.

2 : Department of Dermatology, CHU Rennes, University of Rennes 1, INSERM CIC1414, UPRES EA 7449 REPERES (Pharmacoepidemiology and access to health care), University Rennes 1 and French School of Public Health, Rennes, France.

3: Department of Rheumatology, CHU Rennes, INSERM, INRA, Institut NUMECAN

(Nutrition Metabolism and Cancer), 35000, Rennes, France

4: Department of Radiology, CHU Rennes, France

5 : Department of Rheumatology, CH Dinan, Dinan, France

6 : University of Rennes, CHU Rennes, Inserm, EHESP, Irset (Institut de recherche en santé, environnement et travail) - UMR_S 1085, F-35000, Rennes, France.

\title{
*Corresponding author:
}

Alain Lescoat

Department of Internal Medicine and Clinical Immunlogy, CHU Rennes, South Hospital, 16 bvd de Bulgarie - 35203 RENNES Cedex 2 - BP 90347

E-Mail: alain.lescoat@chu-rennes.fr

Phone: +33299267128 fax : +33299267198

\section{Conflict of interest:}

Leila Caillault, François Robin, Marine Tas, Guillaume Coiffier, Alain Lescoat declare no conflict of interest.

Catherine Droitcourt reports honoraria from Sanofi-Genzyme, $<10.000 \$$, outside of this study.

Funding statement: This study did not receive any financial support

Authors' contributions: Leila Caillault and Alain Lescoat wrote the first draft of the manuscript, François Robin, Marine Tas, Guillaume Coiffier \& Catherine Droitcourt corrected and added substantial modifications to the manuscript.

Word count: 493 /500 
We read with great interest the article by Fairchild and colleagues on ultrasound (US) evaluation of the hands and wrists in patients with systemic sclerosis (SSc)[1]. In this article based on the US evaluation of $43 \mathrm{SSc}$ patients, inflammatory arthritis defined by a score $>0$ using semiquantitative gray scale associated with a score $>0$ using power doppler was noticed in $18.6 \%$ of SSc patients. This prevalence is consistent with previous ultrasound studies in scleroderma[2,3]. Fairchild and colleagues also highlighted the high concordance of osteophytes with GS synovial hypertrophy and tender joints which may suggest that osteophytosis could be a significant contributor to synovial involvement in SSc patients[1]. Interestingly, the authors mentioned the presence of tenosynovial hypertrophy in $30.2 \%$ of SSc patients and reported fibrotic appearing hyperechoic tendon sheaths in the wrist extension tendons in $60.5 \%$ of the cases. Although the definition of inflammatory arthritis is thoroughly discussed, no specific US definition of this fibrotic appearing tenosynovial involvement is given in the methods and/or in the discussion in Fairchild and colleagues' article.

Sclerosing tenosynovitis is a recently described entity, classically characterized in ultrasound examination as the multilayered artichoke heart or onion bulb sclerosing pattern[2-4]. US characteristics of sclerosing tenosynovitis include an iso- or hyperechoic hypertrophy of the tendon sheath with concentric alternating iso- and/or hyperechoic layers. This tenosynovial involvement has been reported both in extensor and flexor tendon sheaths in SSc patients and is rarely associated with inflammatory activity when assessed by power doppler[2]. This fibrotic pattern may be as frequent as inflammatory arthritis in SSc patients[2]. Fibrotic/sclerosing tenosynovitis is more frequent in patients with the diffuse cutaneous subset (dcSSc), and could participate to the phenomenon of tendon friction rubs in this population[2,5]. Although mostly considered specific to SSc, such sclerosing/fibrotic tenosynovitis has been recently described in linear morphea in children [6,7]. This existence of fibrotic tenosynovitis in pediatric cases challenges the hypothesis that osteophytosis could participate in the pathogenesis of fibrotic tenosynovitis, considering the low prevalence of osteophytes in this younger population. Therefore, when assessing tenosynovial hypertrophy and US gray scale scoring in patients with 
decipher the mechanisms of articular involvement notably when considering the interplays between osteophytosis and tenosynovial hypertrophy. To date, contrarily to the OMERACT definition of inflammatory arthritis, there is no consensus definition of tenosynovial fibrotic pattern in SSc and related disorders. We agree with Fairchild and colleagues that "given the challenges of physical exam, musculoskeletal ultrasound is a powerful tool to evaluate the spectrum of articular disease in patients with SSc and should be incorporated into future studies." Such a future incorporation of US parameters in SSc trials and observational studies will require a specific definition and assessment of psychometric properties of each US parameters, such as tenosynovial patterns[3], but also vascular features including ulnar artery occlusion, as mentioned in Fairchild's study, or US finger pulp-blood flow $[1,8-10]$.

\section{References}

[1] Fairchild R, Horomanski A, Sharpless L, Chung M, Li S, Hong J, et al. Ultrasound evaluation of the hands and wrists in patients with systemic sclerosis: Osteophytosis is a major contributor to tender joints. Semin Arthritis Rheum 2021;51:735-40. https://doi.org/10.1016/j.semarthrit.2021.04.020.

[2] Lescoat A, Ballerie A, Belhomme N, Cazalets C, de Carlan M, Droitcourt C, et al. Synovial involvement assessed by power Doppler ultra-sonography in systemic sclerosis: results of a crosssectional study. Rheumatology (Oxford) 2018;57:2012-21. https://doi.org/10.1093/rheumatology/key214.

[3] Elhai M, Guerini H, Bazeli R, Avouac J, Freire V, Drapé J-L, et al. Ultrasonographic hand features in systemic sclerosis and correlates with clinical, biologic, and radiographic findings. Arthritis Care Res (Hoboken) 2012;64:1244-9. https://doi.org/10.1002/acr.21668.

[4] Freire V, Bazeli R, Elhai M, Campagna R, Pessis É, Avouac J, et al. Hand and wrist involvement in systemic sclerosis: US features. Radiology 2013;269:824-30.

https://doi.org/10.1148/radiol.13121994.

[5] Avouac J, Walker UA, Hachulla E, Riemekasten G, Cuomo G, Carreira PE, et al. Joint and tendon involvement predict disease progression in systemic sclerosis: a EUSTAR prospective study. Ann Rheum Dis 2016;75:103-9. https://doi.org/10.1136/annrheumdis-2014-205295.

[6] Merlin E, Breton S, Fraitag S, Stéphan J-L, Wouters C, Bodemer C, et al. Fibrous Arthropathy Associated With Morphea: A New Cause of Diffuse Acquired Joint Contractures. Pediatrics 2017;140:e20161899. https://doi.org/10.1542/peds.2016-1899.

[7] Zulian F, Vallongo C, Woo P, Russo R, Ruperto N, Harper J, et al. Localized scleroderma in childhood is not just a skin disease. Arthritis Rheum 2005;52:2873-81.

https://doi.org/10.1002/art.21264.

[8] Lescoat A, Yelnik CM, Coiffier G, Wargny M, Lamotte C, Cazalets C, et al. Ulnar Artery Occlusion and Severity Markers of Vasculopathy in Systemic Sclerosis: A Multicenter Cross-Sectional Study. Arthritis \& Rheumatology (Hoboken, NJ) 2019;71:983-90.

https://doi.org/10.1002/art.40799.

[9] Lescoat A, Coiffier G, de Carlan M, Droitcourt C, Ballerie A, Cazalets C, et al. Combination of Capillaroscopic and Ultrasonographic Evaluations in Systemic Sclerosis: Results of a CrossSectional Study. Arthritis Care Res (Hoboken) 2018;70:938-43. https://doi.org/10.1002/acr.23413. [10] Lescoat A, Coiffier G, Rouil A, Droitcourt C, Cazalets C, de Carlan M, et al. Vascular Evaluation of the Hand by Power Doppler Ultrasonography and New Predictive Markers of Ischemic Digital Ulcers in Systemic Sclerosis: Results of a Prospective Pilot Study. Arthritis Care Res 


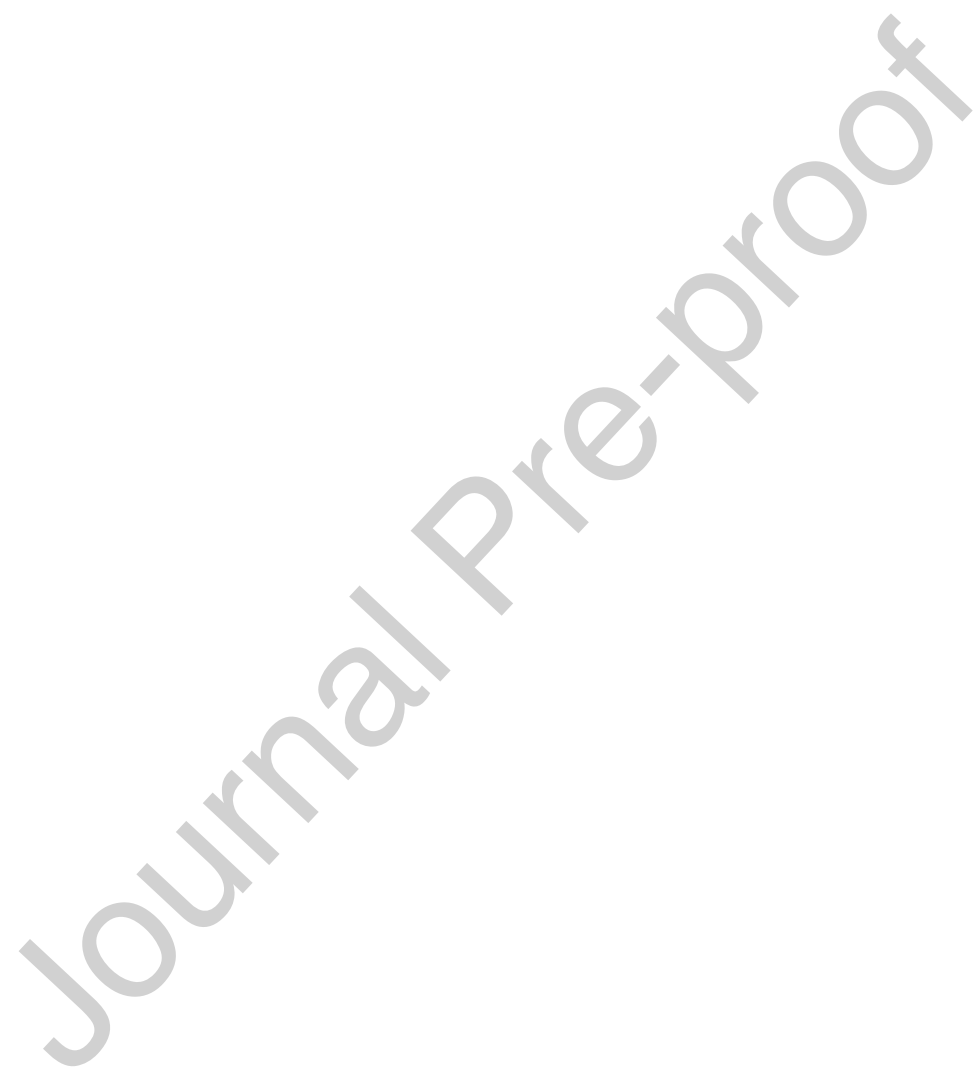

